\title{
A MICROCOMPUTER BASED DECISION SUPPORT TOOL FOR ASSIGNING DOCK DOORS IN FREIGHT YARDS
}

\author{
Louis Y. Tsui and Chia-Hao Chang \\ Department of Industrial and Systems Engineering \\ University of Michigan-Dearborn \\ Dearborn, Michigan 48128
}

\begin{abstract}
ABSTRACI
This paper addresses issues at the shipping/receiving dock of a shipping company, where trucks come in from venders, get their shipments unloaded and reloaded onto trucks going to the customers. The assignment of dock doors to incoming and outgoing trucks determines the efficiency of the dock operation. A microcomputer based tool based on a bilinear program is proposed for recognition of the shipping pattern, and the assignment of the dock doors.
\end{abstract}

\section{INTRODUCTION}

A large shipping company has several freight yards, located at different cities throughout the country. Inbound trucks arrive at the yard with shipments from venders and/or other freight yards, the shipments are sorted according to their destination, and loaded onto outbound trucks that make delivery to the customers. The shipments are processed in the shipping/receiving dock, which is rectangular in shape with hundreds of doors along the longer sides. For management purposes, one side of the dock is designated to the inbound trucks and the other side is designated to the outbound trucks. When a full truck comes in, it gets assigned an available receiving door. The truck driver drops the trailer and leaves the yard with another trailer for his/her next assignment. Each trailer is assigned to a forklift driver, who is responsible for unloading the entire contents from it and loading them to different empty trailers according to their destination. The empty trailers are parked at the shipping doors, with each door assigned to a particular destination. Once the trailer is full, it is hauled away and replaced with another empty one going to the same destination. Therefore, depending on the distance between the receiving door and the shipping door, the time required to empty a trailer can vary significantly. No storage is provided at the freight yard, all shipments must be processed the same day they arrive, and they go directly from the inbound trailer to the outbound trailer to minimize the potential of being damaged. Since the longer it takes to empty the trailer, the more forklifts are required and the more congested the dock will be, the industrial engineers must assign the doors properly in order for the dock to operate efficiently.

There are a relatively large number of studies on truck routing and dispatching, for example, [Brown et al. 87], [Powell et al. 88], but not on the operation of the individual freight yards. At present, all the decisions are made manually. Although everything is under control, the management recognizes that shipping pattern changes from time to time. If the assignment of doors can be adjusted accordingly, the shipments can be processed with less resources. However, to analyze the data manually and consider alternative door assignments with hundreds of doors involved is very time consuming. Therefore, the following computer based tool is recommended.

\section{THE APPROACH}

Each shipping door is assigned only one 
destination so that the chances of items being shipped to wrong destinations are minimized. Thus, the distance traveled by forklifts can be reduced, if the doors assigned to the destination of the items in a trailer is close by the receiving door where the trailer is parked. Currently the inbound truck is assigned to an available receiving door upon arrival, since no prior knowledge on its content is available. However, if we knew the majority of the contents are going to a particular destination, it would be better to assign that inbound truck to a receiving door, which is close to the shipping door assigned to that particular destination. The company has records on the size, weight, origin and destination for each item shipped. Therefore, total weight and volume can be compiled on the amount of items coming from each origin, to derive a distribution of their destinations. This information is later used to estimate the destination of the contents of inbound trucks for better assignments of receiving doors. If the information is compiled monthly, it can also be compared with that from the previous months to produce reports on the change of shipping pattern. When the change is significant, reassignment of the dock doors should be considered.

\section{THE MODEL}

Let there be I receiving doors, $J$ shipping doors, $\mathrm{M}$ origins, and $\mathrm{N}$ destinations. Without loss of generality, we can assume that $I \geq M$ and $J \geq N$. If and when the assumption does not hold, the origin and/or destination must be redefined to include a larger area. Let $d_{i j}$ be the distance between receiving door $i$ and shipping door $j$. Let $X_{m i}=1$ if origin $m$ is assigned to receiving door $i, X_{m i}=0$ otherwise. Let $Y_{n j}=1$ if destination $n$ is assigned to shipping door $\mathrm{j}, \mathrm{Y}_{\mathrm{nj}}=0$ otherwise. The objective here is to find an assignment of receiving doors to the origins and shipping doors to the destinations, such that the distance traveled by the forklifts is minimized. Since the forklift drivers usually move two smaller items a time in order to save one trip, a heuristic formula can be used to convert the above mentioned weight and volume distribution into the number of forklift trips required. Let the number of forklift trips required to move the items originated from $m$ to destination $n$ be denoted as $w_{m n}$. The problem can be formulated as below.

$$
\begin{aligned}
& \text { Minimizing } f(X, Y)=\sum_{i} \sum_{i} \sum_{n} \sum_{m} w_{m n} d_{i j} X_{m i} Y_{n j} \\
& \text { Subject to } \\
& \sum_{n} X_{m i}=1 \text { for } i=1,2 \ldots I \\
& \sum_{m i} X_{m i}=1 \text { for } m=1,2 \ldots M \text { (2) } \\
& \sum_{n j} Y_{n j}=1 \text { for } j=1,2 \ldots J \\
& \sum_{i} Y_{n j}=1 \text { for } n=1,2 \ldots N \quad \text { (4) } \\
& X_{m i}=0 \text { or } 1 \text { for all } m, i \\
& Y_{n j}=0 \text { or } 1 \text { for all } n, j
\end{aligned}
$$

Since there are $w_{m n}$ forklift trips from origin $m$ to destination $n$, if origin $m$ is assigned to door $i$ and destination $n$ is assigned to $\mathrm{j}$, the total distance traveled will be $w_{m n} d_{i j}$, hence, the objective function sums up the total distance traveled from all receiving doors to shipping doors according to the distribution $\mathrm{w}_{\mathrm{mn}}$. Constraint set (1) guarantees that each receiving door is assigned to only one origin, constraint set (2) guarantees that each origin gets assigned a receiving door. Constraint set (3) restricts that each shipping door is assigned to only one destination, and constraint set (4) guarantees that each destination gets assigned a shipping door.

If given either the origin to receiving door assignment $\left(X_{\mathrm{mi}}\right)$ or the destination to shipping door assignment $\left(Y_{n j}\right)$, the remaining problem becomes a standard assignment problem and is quite easy to solve [Spivey and Thrall, 70]. However, when both the $X_{m i}$ and $Y_{n j}$ are unknown, it is a bilinear program [Vaish and Shetty, 76]. Although cutting plane [Vaish and Shetty, 77], [Gallo and Ulkucu, 77] or 
branch and bound algorithms [Falk, 73] can be used to generate the global optimal solution, the implementation of such an algorithm is costly. A local optimal solution based on Vaish and Shetty can be easily implemented on PC, and provides insights and concrete measures for evaluating alternative assignments quickly. The algorithm is stated below.

Step 1. Make an initial assignment $X^{1}$ of origins to receiving doors.

Step 2. a) Find the optimal solution $Y^{1}$ which minimizes $f\left(X^{1}, Y\right)$.

b) Find the optimal solution $X^{2}$ which minimizes $f\left(X, Y^{1}\right)$.

Step 3. Let $X^{1}$ equal to $X^{2}$, repeat step 2 until the procedure converges to a point $\left(X^{\star}, Y^{\star}\right)$.

Since the solution $\left(X^{*}, Y^{*}\right)$ is a local optimal solution, it is clear that $f\left(X^{*}, Y^{*}\right)$ depends on the initial assignment $X^{1}$. One can examine $X^{*}$, modify it and go through the above algorithm again with the modified $X$ as the initial assignment, which is the approach taken to find the global optimal.

\section{DISCUSSION}

The following are worth pointing out.

1. With a user-friendly front end, one can easily fix any assignment as required by the management or by other considerations. The remaining problem can be solved with the same algorithm and the total distance will provide a concrete measure for comparison purposes. Given the velocity of the forklifts, the distance can be translated into terms of time or man-hour, which are more easily to conceptualize.

2. By looking at the amount of items going to a particular destination, it might be desirable to assign more than one shipping door to that destination to reduce the amount of traffic in front of that door. In such a situation, the destination can be divided into several destinations according to the location of customers involved and the amount of shipment they receive. For example, if two dock doors are desired for shipments to Detroit, one door can be assigned to shipment going to the north part of Detroit and the other door can be assigned for shipment to the south part of Detroit. This will also reduce the amount of traveling on the outbound trucks.

3. Although both the receiving and shipping doors must be considered in this problem, the focus is on the resulting shipping door assignments, which stays fixed until the shipping pattern changes. On any particular day, because the venders have different shipping schedules to their customers, for example, once a week or every other day, the contents of the inbound truck might deviates from our estimated distribution significantly. If the the contents can be scanned at the gate before a door is assigned, the operation can be further improved.

\section{CONCLUSION}

The closer to the daily operation, the more dynamic and the less well defined the problem is. A detailed model usually needs a large amount of up-to-date data, which is seldom available. A detailed model also requires modification when new constraints must be considered. In situations where support for daily data entry or program development and maintenance is unavailable, decision must be made by people on the job with realistic constraints. Most people at this level can rely only on their experience and at most, a calculator for decision making. The model we proposed does not attempt to come up with the optimal solution, it provides the basic calculations and recommends a good starting point. The result can be applied directly, or modified and used as the initial assignment for another iteration. With the time it saves, it allows the decision maker to consider more alternatives and select the best one under the right circumstances. We strongly believe computer applications in this direction will serve the best interest of all industrial engineers. 


\section{REFERENCES}

Powell W.B., Y. Sheffi, K.S. Nickerson, K.Butterbaugh, S. Atherton, "Maximizing Profits for North American Van Line's Truckload Division: A New Framework for Pricing and Operations," Interfaces, Vol. 18, No. 1, 1988.

Brown G.G, C.J. Ellis, G.W. Graves, D. Ronen, "Real-time Wide Area Dispatch of Mobil Tank Trucks," Interfaces, Vol. 17, No. 1, 1987.

Vaish H, C.M. Shetty, "A Cutting Plane Algorithm For The Bilinear Programming Problem," Naval Research Logistics Quarterly, Vol 24, 1977.

Gallo G., Ulkulu A., "Bilinear Programming: An Exact Algorithm," Mathematical Programming, Vol 12, 1977.

Vaish H, C.M. Shetty, "The Bilinear

Programming Problem," Naval Research Logistics Quarterly, Vol 23, 1976.

Falk J.E., "A Linear Max-Min Problem," Mathematical Programming, Vol 5, 1973.

Spivey, W.A., R.M. Thrall, Linear Optimization, Chap. 6, Holt, Rinehart \& Wilson, New York, 1970. 